\title{
Clinical Study \\ Diagnosis of Asthma in Primary Health Care: A Pilot Study
}

\author{
Karin C. Ringsberg, ${ }^{1,2}$ Paula Bjärneman, ${ }^{2}$ Ronny Larsson, ${ }^{3}$ \\ Elisabeth Wallström, ${ }^{3}$ and Olle Löwhagen ${ }^{2}$ \\ ${ }^{1}$ Nordic School of Public Health, 40242 Gothenburg, Sweden \\ ${ }^{2}$ Sahlgrenska Academy, University of Gothenburg, 41390 Gothenburg, Sweden \\ ${ }^{3}$ Kungsten Health Care Centre, 41474 Gothenburg, Sweden \\ Correspondence should be addressed to Karin C. Ringsberg; karin.ringsberg@gu.se
}

Received 6 September 2013; Revised 5 March 2014; Accepted 16 March 2014; Published 10 April 2014

Academic Editor: Steven Nordin

Copyright ( 2014 Karin C. Ringsberg et al. This is an open access article distributed under the Creative Commons Attribution License, which permits unrestricted use, distribution, and reproduction in any medium, provided the original work is properly cited.

\begin{abstract}
Some patients with an asthma diagnosis have a poor controlled asthma. One explanation may be an incorrect diagnosis. Aim. The aim of the study was to diagnose and classify patients with non-infectious lower respiratory tract problems in primary health care using internationally applied diagnostic criteria and diagnostic tests. Patients and Methods. New adult patients visiting a primary

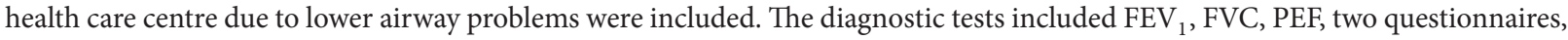
methacholine test, and skin prick test. Results. The patients $(n=43)$ could be divided into four groups: asthma $(28 \%)$, asthma-like disorder (44\%), idiopathic cough (12\%), and a nonreversible bronchial obstructive group (16\%). The asthma and asthma-like groups showed similar patterns of airway symptoms and trigger factors, not significantly separated by a special questionnaire. Phlegm, heavy breathing, chest pressure/pain, cough, and wheezing were the most common symptoms. Physical exercise and scents were the dominating trigger factors. Conclusions. Nonobstructive asthma-like symptoms seem to be as common as bronchial asthma in primary health care. Due to the similarities in symptoms and trigger factors the study supports the hypothesis that asthma and nonobstructive asthma-like disorders are integrated in the same "asthma syndrome," including different mechanisms, not only bronchial obstruction.
\end{abstract}

\section{Introduction}

Bronchial asthma is a common disease worldwide and good treatment could often be offered [1]. Its prevalence in the adult population in Sweden is up to $10 \%[2]$, being the highest in the north part and in younger people. The diagnosis is based on the presence of episodic breathing troubles and variable and reversible airway obstruction $[1,3]$. Most cases are not difficult to diagnose and treat; however, some patients respond poorly to asthma treatment despite ongoing asthmalike symptoms. In those cases, other diagnoses must be considered [4-15]. Disorders with asthma-like symptoms mentioned in the literature are dysfunctional breathing [11, 16-18], vocal cord dysfunction [19], pseudoasthma [20], cough variant asthma [8], multiple chemical sensitivity [21], and airway sensory hyperreactivity (SHR) [22]. In GINA, the international guidelines for asthma diagnostics and treatment [1], two disorders with asthma-like symptoms are mentioned, vocal cord dysfunction (VC) [19] and hyperventilation syndrome (HVS) [7]. As the above conditions are presented under different names, it is not possible to know the prevalence. However, Marklund et al. found that every third asthmatic had been given a wrong diagnosis [14]. They also found that the older the patients, the greater the risk of an incorrect diagnosis [14]. Johansson et al. [23] estimated the prevalence of airway sensory hyperreactivity to be about $6 \%$ in the adult population. These patients often seek primary care because of asthma-like symptoms and poor quality of life [5]. Using factor analysis in a general population sample Bonde et al. [18] identified five groups of breathingrelated disorders, dysfunctional breathing, odour intolerance, asthma, bronchitis, and a group with mixed symptoms. These groups should therefore be considered when investigating patients in the primary care.

In this study, an operational definition of asthma-like disorder is used, meaning symptoms that most physicians 
associate with asthma but where abnormal lung function cannot be demonstrated [10]. The term asthma-like disorder is henceforth used.

Aim. The aim of this pilot study, preceding a larger study, was to diagnose and classify adult patients with noninfectious lower respiratory tract problems in primary health care by using international applied diagnostic criteria.

\section{Patients and Methods}

The study was performed at a primary health care centre in Sweden in a city with about half a million inhabitants. The health care centre served about 12,000 inhabitants with intermediate to high incomes. Four GPs and five nurses worked at the centre. One of the nurses and one of the physicians were specially trained in asthma and respiratory diseases.

2.1. Patients. Consecutive patients who visited the health care centre for the first time over a period of one year were included.

2.1.1. Inclusion Criteria. Inclusion criteria included the following:

(1) male or female, age $\geq 17$,

(2) respiratory symptoms from lower airways persisting for more than one month in order to exclude patients with short term symptoms,

(3) not earlier diagnosed for these symptoms.

2.1.2. Exclusion Criteria. Exclusion criteria included the following:

(1) previously diagnosed airway disease (asthma, COPD, alveolitis, bronchiectasis, sarcoidosis, etc.),

(2) ongoing airway infection,

(3) other diseases that could influence the lower airways and chest mobility (heart disease, systemic immunological disease, osteoporosis, pulmonary emboli, etc.).

\subsection{Methods}

2.2.1. Lung Function Test. Lung function test included the following:

(1) $\mathrm{FEV}_{1}$ before and after inhalation of salbutamol $0.8 \mathrm{mg}$ (reversibility) [1],

(2) PEF morning and evening, before and after inhaled salbutamol $0.4 \mathrm{mg}$ over a period of two weeks (variability) [1],

(3) FVC and VC (obstruction) [1].

FEV\% was calculated as FEV1/FVC or FEV1/VC (if VC was higher than FVC) after bronchodilation [24].
Lung function was measured by volume-dependent spirometry (Vitalograph) with normal reference values from Standardization of Lung Function Tests (Bull Europ. Physiopath. Resp.1983:19 suppl). PEF was measured by a Mini wright peak flow meter. All tests were performed in the same way in each patient.

As the patients included in the study were new patient they had no treatment, neither before nor during the investigation. They were prescribed therapy after completed investigation.

2.2.2. Skin Prick Test. The skin prick test was performed on patients who reported a suspected allergy history. A standard panel of 10 allergen extracts (Soluprick SQ ALK Copenhagen) was used (two mites, two moulds, birch, mugwort, timothy, cat, dog, horse).

2.2.3. Methacholine Test. Patients with unclear lung function data or values close to pathological limit were referred to an asthma-allergy clinic for a methacholine inhalation test. A positive test was defined as $\mathrm{PC}_{20}$ (provocation concentration at $20 \%$ fall in $\mathrm{FEV}_{1} \leq 4 \mathrm{mg} / \mathrm{mL}$ ) [25].

2.2.4. Questionnaire. Two questionnaires were used. One general questionnaire, number 1 (see Tables 2 and 5), used for several years in the clinic included common symptoms (cough, wheezing, heavy breathing, phlegm, and chest pressure/pain) and common trigger factors (cold air, physical exercise, smoke, strong scents, emotional stress, and allergens). The patients were asked to answer yes or no. The second questionnaire, number 2 , included 21 symptoms and 7 trigger factors (see Tables 3 and 6) and had earlier been designed to separate asthma from asthma-like disorders in patients referred to a special clinic for asthma and allergy [26]. The patient was asked to rate the frequency of symptoms on a five-point Likert scale: 1 = never, 2 = occasionally, $3=$ once a month, $4=$ once a week, and $5=$ daily and the severity of the trigger factors on a five-point Likert scale: $1=$ not at all, $2=$ some, $3=$ rather a lot, $4=$ much, and $5=$ very much. One question in the original version of questionnaire number 2 (strong scents) was excluded as it was also included as a trigger factor. Symptoms presented in questionnaire number 2 (Table 3) were grouped into five subsets of symptoms [26]: "upper airways nose throat", "lower airways-chest", "general symptoms", "stomach", and "sleep".

2.2.5. Diagnostic Criteria. For bronchial asthma, COPD, and chronic cough, international approved criteria were used [1, $24,25]$. For asthma-like disorders, criteria were set up on the basis of earlier studies [4, 9-11, 14, 15].

Bronchial Asthma [1]. Bronchial asthma included the following:

(1) episodic lower airway symptoms (breathing complaints, wheezing, coughing, phlegm, chest tightness, or chest pain/pressure) [1], 
TABLE 1: Age, sex, lung function, and classification of patients.

\begin{tabular}{|c|c|c|c|c|c|}
\hline Group & $\begin{array}{l}\text { Age median } \\
\text { (range) }\end{array}$ & $\begin{array}{c}\text { Sex } \\
\text { male/female }\end{array}$ & $\begin{array}{l}\mathrm{FEV}_{1} \% \text { predicted } \\
\text { mean (range) }\end{array}$ & $\begin{array}{c}\mathrm{FEV}_{1} \text { reversibility mean } \\
\% \text { (range) }\end{array}$ & $\begin{array}{c}\text { PEF variability } \\
\text { mean } \% \\
\text { (range) }\end{array}$ \\
\hline $\begin{array}{l}\text { (I) Asthma } \\
N=12\end{array}$ & $44(36-83)$ & $0 / 12$ & $99(76-123)$ & $6(0-13)$ & $24(8-52)$ \\
\hline $\begin{array}{l}\text { (II) Asthma-like } \\
N=19\end{array}$ & $47(19-76)$ & $3 / 16$ & $103(91-122)$ & $2(0-8)$ & $10(7-19)$ \\
\hline $\begin{array}{l}\text { (III) Idiopathic cough } \\
N=5\end{array}$ & $50(39-57)$ & $0 / 5$ & $103(95-107)$ & $3(0-7)$ & $11(2-15)$ \\
\hline $\begin{array}{l}\text { (IV) Nonreversible bronchial } \\
\text { obstructive } \\
N=7\end{array}$ & $59(17-66)$ & $2 / 5$ & $79(73-86)$ & $4(0-11)$ & $11(5-16)$ \\
\hline
\end{tabular}

(2)

(a) reversibility of $\mathrm{FEV}_{1} \geq 12 \%$ [1],

(b) variability in $\mathrm{PEF} \geq 20 \%[1]$.

Asthma-Like Disorders [4, 9-11, 14, 15, 26]. Asthma-like disorders include the following:

(1) episodic lower airway symptoms (breathing complaints, wheezing, coughing, phlegm, chest tightness, or chest pain/pressure),

(2) reversibility in $\mathrm{FEV}_{1}<12 \%$,

(3) $\mathrm{FEV}_{1} \geq 90 \%$ of normal predicted value,

(4) variability in $\mathrm{PEF}<20 \%[4,9]$.

COPD [24] . COPD included the following:

(1) lower airway symptoms (breathing complaints, wheezing, coughing, phlegm, chest tightness, and chest pain/pressure),

(2) reversibility in $\mathrm{FEV}_{1}<12 \%$,

(3) variability in $\mathrm{PEF}<20 \%$,

(4) $\mathrm{FEV} \%<70 \%\left(\mathrm{FEV}_{1} / \mathrm{FVC}\right.$ or $\mathrm{FEV}_{1} / \mathrm{VC}$ if $\mathrm{VC}$ was higher than FVC) after bronchodilation.

Chronic Idiopathic Cough [27] . Chronic idiopathic cough included the following:

(1) dominant cough lasting $\geq 8$ weeks,

(2) $\mathrm{FEV}_{1} \geq 90 \%$ of predicted normal value,

(3) reversibility in $\mathrm{FEV}_{1}<12 \%$,

(4) variability in PEF $<20 \%$.

2.3. Statistics. Within-group comparisons in questionnaire number 1 (yes/no answers) were analysed using the chisquare test. The statistical analysis focused on the difference between asthma and asthma-like disorders. For differences between groups, nonparametric methods were used; for

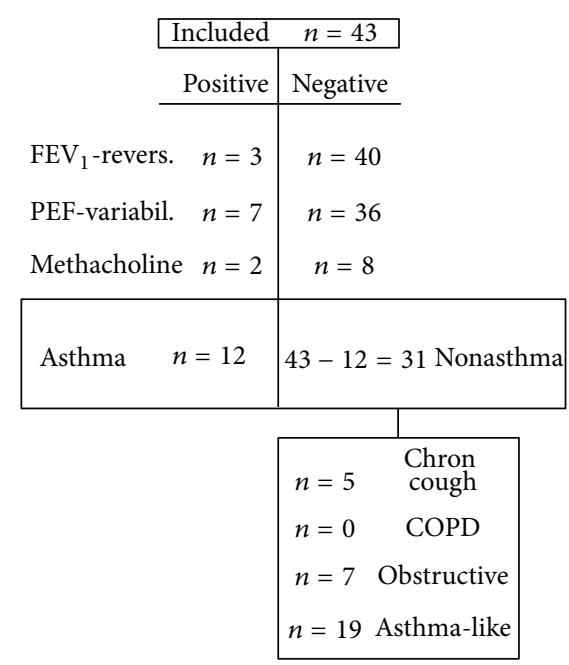

Figure 1: Flow chart. Classification to different groups (see Section 3) depending on $\mathrm{FEV}_{1}$-reversibility, PEF-variability, and methacholine test.

questionnaire number 2, the Wilcoxon signed-ranks test was used and for comparisons between Group I and II, Mann Whitney's test was used. $P<0.05$ was considered to be statistically significant.

\section{Results}

Of the 537 patients visiting the centre because of airway symptoms eight percent $(n=43)$ fulfilled the inclusion criteria for the study. Characteristics are shown in Table 1 and Figure 1 (flow chart).

3.1. Classification. Based on the diagnostic criteria above, the patients (38 women and 5 men, aged 17-83, median 54) were divided into four groups; (Group I) asthma (28\%), (Group II) asthma-like (44\%), (Group III) chronic idiopathic cough (12\%), and (Group IV) nonreversible bronchial obstructive group (16\%). No patient fulfilled the criteria for COPD. The median age was the highest in Group IV (59 years) and the lowest in Group I (44 years). The dominant 
TABLE 2: The five most reported symptoms based on questionnaire no. 1. Group I-IV.

\begin{tabular}{|c|c|c|c|c|}
\hline & $\begin{array}{l}\text { Group I } \\
N=12\end{array}$ & $\begin{array}{c}\text { Group II } \\
N=19\end{array}$ & $\begin{array}{c}\text { Group III } \\
N=5\end{array}$ & $\begin{array}{c}\text { Group IV } \\
N=7\end{array}$ \\
\hline Phlegm & $12(100 \%)$ & $18(95 \%)$ & $4(80 \%)$ & $7(100 \%)$ \\
\hline Heavy breathing & $9(75 \%)$ & $16(84 \%)$ & $0(0 \%)$ & $4(58 \%)$ \\
\hline Chest pressure/pain & $9(75 \%)$ & $9(47 \%)$ & $0(0 \%)$ & $2(29 \%)$ \\
\hline Cough & $2(16 \%)$ & $12(63 \%)$ & $5(100 \%)$ & $3(29 \%)$ \\
\hline Wheezing & $6(50 \%)$ & $7(37 \%)$ & $0(0 \%)$ & $3(43 \%)$ \\
\hline
\end{tabular}

TABLE 3: Frequency of single symptoms scored on questionnaire no. 2.

\begin{tabular}{|c|c|c|c|c|}
\hline Symptom & $\begin{array}{c}\text { Group I } \\
N=12 \\
\text { Median (range) }\end{array}$ & $\begin{array}{c}\text { Group II } \\
N=19 \\
\text { Median (range) }\end{array}$ & $\begin{array}{c}\text { Group III } \\
N=5 \\
\text { Median (range) }\end{array}$ & $\begin{array}{c}\text { Group IV } \\
N=7 \\
\text { Median (range) }\end{array}$ \\
\hline (1) Dry eyes & $1.0(1-4)$ & $1.0(1-4)$ & $1.0(1-1)$ & $1.0(1-1)$ \\
\hline (2) Dry mucus in nose & $2.0(1-5)$ & $2.0(1-5)$ & $1.0(1-4)$ & $2.0(1-5)$ \\
\hline (3) Dry mucus in throat & $2.0(1-5)$ & $2.0(1-5)$ & $1.0(1-5)$ & $3.0(2-5)$ \\
\hline (4) Taste of blood & $1.0(1-2)$ & $1.0(1-4)$ & $1.0(1-2)$ & $1.0(1-1)$ \\
\hline (5) Difficulty in getting air & $2.0(1-5)$ & $3.0(1-5)$ & $1.0(1-4)$ & $2.0(1-3)$ \\
\hline (6) Difficulty in taking deep breaths & $2.0(1-5)$ & $2.0(1-5)$ & $2.0(1-4)$ & $2.0(1-5)$ \\
\hline (7) Wheezing & $2.0(1-5)$ & $2.0(1-5)$ & $1.0(1-2)$ & $1.0(1-4)$ \\
\hline (8) Hissing & $2.0(1-5)$ & $2.0(1-5)$ & $1.0(1-2)$ & $1.0(1-4)$ \\
\hline (9) Feeling of sore airways & $2.0(1-5)$ & $2.0(1-5)$ & $1.0(1-4)$ & $2.0(1-5)$ \\
\hline (10) Irritating cough & $5.0(1-5)$ & $3.0(2-5)$ & $5.0(1-5)$ & $3.0(2-5)$ \\
\hline (11) Nausea & $1.0(1-3)$ & $2.0(1-5)$ & $1.0(1-4)$ & $2.0(1-4)$ \\
\hline (12) Sensation of bloated abdomen & $1.0(1-4)$ & $2.0(1-4)$ & $1.0(1-5)$ & $1.0(1-2)$ \\
\hline (13) Waking up due to nasal congestion & $2.0(1-5)$ & $2.0(1-5)$ & $2.0(1-5)$ & $2.0(1-5)$ \\
\hline (14) Abnormal tiredness, weakness after psychological stress & $2.0(1-5)$ & $2.0(1-5)$ & $1.0(1-4)$ & $2.0(1-4)$ \\
\hline (15) A sore throat & $2.0(1-5)$ & $2.0(1-5)$ & $1.0(1-4)$ & $2.0(1-5)$ \\
\hline (16) Headaches & $2.0(1-4)$ & $2.0(1-5)$ & $3.0(2-4)$ & $2.0(1-3)$ \\
\hline (17) Feeling of confusion & $1.0(1-4)$ & $1.0(1-4)$ & $1.0(1-1)$ & $2.0(1-3)$ \\
\hline (18) Cold hands and feet & $2.0(1-5)$ & $2.5(1-5)$ & $2.0(1-5)$ & $2.0(1-4)$ \\
\hline (19) Feeling of tenseness in the body & $2.0(1-5)$ & $3.0(1-5)$ & $2.0(1-3)$ & $2.5(1-3)$ \\
\hline (20) Difficulty in concentrating & $2.0(1-4)$ & $2.5(1-5)$ & $2.0(1-4)$ & $2.0(1-5)$ \\
\hline
\end{tabular}

sex was female in all groups. Men were only represented in Groups II and IV (Table 1).

Group I. Twelve patients (28\%) fulfilled the diagnostic criteria for bronchial asthma. Two patients (with borderline reversibility or variability) were classified as belonging to this group on the basis of a positive methacholine tests (threshold dose $\leq 4 \mathrm{mg} / \mathrm{Ml}$ ). Four patients had a positive skin prick test.

Group II. Nineteen patients (44\%) fulfilled the criteria for an asthma-like disorder. All patients had a $\mathrm{FEV}_{1}$, reversibility, and PEF variability within normal range. A methacholine test was performed in six cases, and all tests were negative (threshold dose $>16 \mathrm{mg} / \mathrm{mL}$ ).

Group III. Five patients (12\%) fulfilled the criteria for a chronic idiopathic cough. The duration of the cough varied from four months to 10 years. In none of the patients were there clinical signs of a reflux, rhinitis, or sinusitis.
Group IV. Seven patients (16\%) had a bronchial obstruction, varying in $\mathrm{FEV}_{1}$ from $73 \%$ to $86 \%$ predicted; however, without reversibility or variability. None of them was a smoker, none had an allergy, and none fulfilled the criteria for COPD. One patient was classified as belonging to this group on the basis of a negative methacholine test. The investigation of these obstructive patients continued and ended with the following final diagnoses: two patients with infection-induced asthma, one with asthma and lung cancer, one with probable asthma and unclear resting dyspnea, one with bronchiectasis, one with asthma, diaphragmatic hernia, and reflux, and one patient with obstruction, chronic cough, and phlegm.

3.2. Skin Prick Test. Eleven patients reported a positive allergy history with airway complaints. Five of these patients had a negative skin prick test and were considered nonallergic. Of the six patients with a positive test, four were found 
TABLE 4: Subsets of symptoms scored in questionnaire no. 2.

\begin{tabular}{|c|c|c|c|c|}
\hline Subsets of symptoms (questions number) & $\begin{array}{c}\text { Group I } \\
N=12 \\
\text { Median (range) }\end{array}$ & $\begin{array}{c}\text { Group II } \\
N=19 \\
\text { Median (range) }\end{array}$ & $\begin{array}{c}\text { Group III } \\
N=5 \\
\text { Median (range) }\end{array}$ & $\begin{array}{c}\text { Group IV } \\
N=7 \\
\text { Median (range) }\end{array}$ \\
\hline Upper airways, eyes, nose, throat $(1,2,3,4)$ & $2.0(1-5)$ & $1.0(1-5)$ & $1.0(1-5)$ & $1.0(1-5)$ \\
\hline Lower airways $(5,6,7,8,9,10)$ & $2.0(1-5)$ & $2.0(1-5)$ & $1.0(1-5)$ & $2.0(1-5)$ \\
\hline General symptoms $(16,17,18,19,20)$ & $2.0(1-5)$ & $2.0(1-5)$ & $2.0(1-5)$ & $2.0(1-5)$ \\
\hline Stomach $(11,12)$ & $1.0(1-4)$ & $2.0(1-5)$ & $1.0(1-5)$ & $1.0(1-4)$ \\
\hline Sleep $(13,14)$ & $2.0(1-5)$ & $2.0(1-5)$ & $2.0(1-5)$ & $2.0(1-5)$ \\
\hline
\end{tabular}

in Group I (pollen, cat, dog, and mite) and two in Group II (pollen, cat, and dog). The results of the skin prick test did not change the classification of the patients.

\subsection{Symptoms}

Questionnaire Number 1. The most common symptom reported in all groups was phlegm (Table 2). Cough was, by definition, the most common symptom in Group III. The second most common symptom was chest pressure/pain (Group I) and heavy breathing (Groups II and IV). Wheezing, often considered to be a criterion for asthma, was reported by $50 \%$ of Group I and by $37 \%$ of Group II. There were no significant differences between Groups I and II for any of the five most common symptoms.

Questionnaire Number 2. There were no significant differences in symptoms of breathing troubles (wheezing, hissing, difficulty in getting air, and difficulty in taking deep breaths) between Groups I and II (Table 3).

When symptoms in questionnaire number 2 were grouped into five subsets of symptoms [26]: "upper airways" (eye, nose, throat), "lower airways", "general symptoms", "stomach", and "sleep", no significant differences between Groups I and II were found (Table 4).

\subsection{Trigger Factors}

Questionnaire Number 1. The most common trigger factor in all the groups was physical exercise (walking up hills/stairs) and cold air (Table 5). There were no statistically significant differences between Groups I and II for any of these seven factors.

Questionnaire Number 2. The total median score of trigger factors in questionnaire number 2 (Table 6) for Group I was 1.7, for Group II 1.6, for Group III 1.1, and for Group IV 2.5. Thus, there was no difference between Groups I and II. The highest median score was seen in Group IV, "some" to "rather a lot."

\section{Discussion}

Most patients with respiratory complaints in Sweden are first visiting the primary health care, which has good access to practical and reliable diagnostic methods. The number of new patients in this one-year study was in line with a reported incidence of $2 \%$ of adult asthma [28] in this area. Accordingly, we believe that the results could be generalized to a larger population. Bronchial asthma and COPD are reported to be the most common chronic lower airway diseases $[1,3,24]$. In this clinical study in primary health care, the picture was different. A clear bronchial asthma was found in $28 \%$ while the majority had other respiratory complaints, asthma-like (44\%), chronic idiopathic cough (12\%), and nonreversible bronchial obstruction (16\%). If five patients (possibly asthma) in the unclear obstructive group were added to the asthma group, the prevalence of asthma and asthma-like disorders was approximately the same. Similar findings are reported in another study in the primary care [14]. The results are also supported by a recent epidemiological study by Bonde et al. [18]. By use of factor analysis five groups of breathing related symptoms were identified, asthma, bronchitis, dysfunctional breathing, odour intolerance, and a mixed group. As the patients included in the study were new patients they had no treatment, neither before nor during the investigation. The patients were prescribed therapy after completing the investigation.

An asthma-like disorder may be an early stage of bronchial asthma or bronchial asthma in a temporary symptom-free stage with normal lung function. However, it has been shown that a disorder with asthma-like symptoms and normal lung function may persist for more than 5 years $[29,30]$. New cases of COPD were not found during this study period which was somewhat unexpected. However, this may be explained by the low percentage of smokers in this area, $10 \%$, compared to $18 \%$ in national epidemiological studies [18]. One or more patients in the obstructive group (group IV) may have incipient COPD but did not fulfil the diagnostic criteria. The non-COPD diagnosis was supported by the fact that none of the patients was a smoker. Another explanation could be obstruction due to remodelling. The extended investigation of the unclear group showed complicated and combined diseases were asthma could be suspected in 5 of the 7 cases.

In international guidelines $[1,3]$ two asthma-like disorders are mentioned as the most common differential diagnoses, vocal cord dysfunction [19], and hyperventilation syndrome $[7,31]$. In this study there were no clear indications of these diseases. Based on the questionnaires and records, no patient reported inspiratory stridor or upper airway symptoms typical of VCD. Hyperventilation syndrome 
TABLE 5: Most reported symptom-inducing trigger factors based on questionnaire no. 1.

\begin{tabular}{|c|c|c|c|c|}
\hline Trigger factor & $\begin{array}{c}\text { Group I } \\
N=12 \\
n(\%)\end{array}$ & $\begin{array}{c}\text { Group II } \\
N=19 \\
n(\%)\end{array}$ & $\begin{array}{c}\text { Group III } \\
N=5 \\
n(\%)\end{array}$ & $\begin{array}{c}\text { Group IV } \\
\begin{array}{c}N=7 \\
n(\%)\end{array}\end{array}$ \\
\hline Walking up hills/stairs & $10(83)$ & $10(53)$ & $2(40)$ & $6(86)$ \\
\hline Cold air & $7(58)$ & $8(42)$ & $3(60)$ & $4(57)$ \\
\hline Mental stress & $3(25)$ & $4(21)$ & $1(20)$ & $4(57)$ \\
\hline Tobacco smoke & $3(25)$ & $7(37)$ & $1(20)$ & $4(57)$ \\
\hline Flowers & $3(25)$ & $4(21)$ & $0(0)$ & $5(71)$ \\
\hline Perfume & $3(25)$ & $0(0)$ & $0(0)$ & $5(71)$ \\
\hline Exhaust gases & $3(25)$ & $3(16)$ & $0(0)$ & $2(29)$ \\
\hline
\end{tabular}

TABLE 6: Severity of symptom induced trigger factors based on questionnaire no. 2 .

\begin{tabular}{|c|c|c|c|c|}
\hline Trigger factor & $\begin{array}{c}\text { Group I } \\
N=12 \\
\text { Median (range) }\end{array}$ & $\begin{array}{c}\text { Group II } \\
N=19 \\
\text { Median (range) }\end{array}$ & $\begin{array}{c}\text { Group III } \\
N=5 \\
\text { Median (range) }\end{array}$ & $\begin{array}{c}\text { Group IV } \\
N=7 \\
\text { Median (range) }\end{array}$ \\
\hline (1) Warm weather & $1.0(1-5)$ & $1.0(1-4)$ & $1.0(1-2)$ & $1.5(1-4)$ \\
\hline (2) Conflicting situations & $1.5(1-4)$ & $1.0(1-4)$ & $1.0(1-3)$ & $1.5(1-4)$ \\
\hline (3) Strong scents & $2.5(1-5)$ & $2.0(1-4)$ & $1.0(1-1)$ & $3.0(2-5)$ \\
\hline (4) Exhaust gases & $2.0(1-5)$ & $2.0(1-4)$ & $1.0(1-3)$ & $3.0(2-5)$ \\
\hline (5) Stuffy air & $2.0(1-4)$ & $2.0(1-3)$ & $1.0(1-1)$ & $3.0(1-5)$ \\
\hline (6) Smell of tobacco & $2.0(1-5)$ & $2.0(1-5)$ & $2.0(1-4)$ & $3.5(2-5)$ \\
\hline (7) Dust from detergent & $1.0(1-4)$ & $1.0(1-3)$ & $1.0(1-1)$ & $2.0(1-5)$ \\
\hline
\end{tabular}

$P=\leq 0.05$.

$[7,31]$ is a well-known asthma-like disorder since many years, but its existence in a chronic form has been contested [31, 32]. However, as it has been clearly demonstrated in acute studies hyperventilation it is still of interest $[12,13,16,17$, 20, 31, 33-36]. By using the Nijmegen questionnaire, often used for identifying hyperventilation syndrome, Thomas et al. [16] recently found that every third woman with an asthma diagnosis had a positive score $(\geq 23)$. The disorder that was identified in this way was not called hyperventilation but dysfunctional breathing. Dysfunctional breathing has also been described in other studies [7, 17, 36]. Some symptoms listed in the Nijmegen questionnaire are also included in questionnaire number 2 [26]: "difficulty in taking deep breaths," "sensation of bloated abdomen," "feeling of confusion," "cold hands and feet," and "feeling of tenseness in the body." Thus, it is likely that the asthma-like disorder found in our study overlaps with the above described dysfunctional breathing. In 1998 the asthma-like disorder airway sensory hyperreactivity (SHR) was described by use of the capsaicin inhalation test [22]. Its prevalence has been reported to be about $6 \%$ [23], which can be compared with the prevalence of asthma of $6-10 \%$ in the same area [2]. This disorder may well be found in Group II in our study, but capsaicin inhalation test is still not available in the primary care.

International guidelines of respiratory diseases focus on asthma and COPD [1, 3]. This study points to the importance of also seeing other nonvariable and nonobstructive asthma-like disorders. The symptoms and trigger factors are very similar to asthma, which makes the differential diagnosing difficult. Bronchial obstruction, reversible and variable, is one mechanism but there might be more forming an "asthma syndrome". This hypothesis is supported by a recent study by Bonde et al. [18]. It is important not to ignore asthma-like disorders even if they do not fit into any diagnostic criterion. The patients are often complaining of poor quality of life and that their symptoms are seen "just as psychological problems". For the moment no medical treatment can be offered. However, alternative treatment inspired by cognitive behavioural therapy has been successful [37-39].

\section{Conclusions}

In conclusion, this study shows that asthma-like symptoms with or without reversible bronchial obstruction are equally common in patients seeking primary health care. The similarities in symptoms and trigger factors support the hypothesis that asthma and nonobstructive asthma-like disorders are integrated in the same "asthma syndrome", which might include different mechanisms, not only bronchial obstruction.

\section{Ethical Approval}

All diagnostic tests were included in the clinical routine at the centre. This pilot study is included in a larger planned study whose design was approved by the local ethical committee (reference no. 615-11). The rules of the Helsinki Declaration 
were followed. Both patients and doctors were carefully informed.

\section{Conflict of Interests}

The authors declare that there is no conflict of interests regarding the publication of this paper.

\section{Acknowledgment}

The authors would like to thank Inger Winberg at the Asthma and Allergy Centre, Sahlgrenska University Hospital, for performing the methacholine tests.

\section{References}

[1] Global Initiative for Asthma (GINA), National Institutes of Health. National Heart, Lung, and Blood Institute. Revised 2004, http://www.ginasthma.com.

[2] B. Lundbäck, "Epidemiology of rhinitis and asthma," Clinical and Experimental Allergy, vol. 28, no. 2, pp. 3-10, 1998.

[3] M. L. Levy, M. Fletcher, D. B. Price, T. Hausen, R. J. Halbert, and B. P. Yawn, "International Primary Care Respiratory Group (IPCRG) Guidelines: diagnosis of respiratory diseases in primary care," Primary Care Respiratory Journal, vol. 15, no. 1, pp. 20-34, 2006.

[4] O. Löwhagen, "Asthma and asthma-like disorders," Respiratory Medicine, vol. 93, pp. 851-855, 1999.

[5] K. C. Ringsberg, K. Segesten, and I. Åkerlind, "Walking around in circles-the life situation of patients with asthma-like symptoms but negative asthma tests," Scandinavian Journal of Caring Sciences, vol. 11, no. 2, pp. 103-112, 1997.

[6] P. J. Barnes and A. J. Woolcock, "Difficult asthma," European Respiratory Journal, vol. 12, no. 5, pp. 1209-1218, 1998.

[7] H. Folgering, "The pathophysiology of hyperventilation syndrome," Monaldi Archives for Chest Disease, vol. 54, no. 4, pp. 365-372, 1999.

[8] S. A. Antoniu, T. Mihaescu, and C. F. Donner, "Pharmacotherapy of cough-variant asthma," Expert Opinion on Pharmacotherapy, vol. 8, no. 17, pp. 3021-3028, 2007.

[9] O. Löwhagen, "Functional respiratory disorders as significant differential diagnosis in asthma," Lakartidningen, vol. 86, no. 12, pp. 57-59, 1989.

[10] K. C. Ringsberg, "Patients with asthma-like symptoms but negative asthma tests and patients with bronchial asthma. Physiological, psychological and social characteristics," Medical Dissertations 522, Linköping University, 1997.

[11] K. C. Ringsberg, O. Löwhagen, and T. Sivik, "Psychological differences between asthmatics and patients suffering from an asthma-like condition, functional breathing disorder: a comparison between the two groups concerning personality, psychosocial and somatic parameters," Integrative Physiological and Behavioral Science, vol. 28, no. 4, pp. 358-367, 1993.

[12] K. C. Ringsberg, H. Wetterqvist, O. Löwhagen, and T. Sivik, "Physical capacity and dyspnea in patients with asthma-like symptoms but negative asthma tests," Allergy, vol. 52, no. 5, pp. 532-540, 1997.

[13] K. C. Ringsberg and I. Åkerlind, "Presence of hyperventilation in patients with asthma-like symptoms but negative asthma test responses: provocation with voluntary hyperventilation and mental stress," Journal of Allergy and Clinical Immunology, vol. 103, no. 4, pp. 601-608, 1999.

[14] B. Marklund, A. Tunsäter, and C. Bengtsson, "How often is the diagnosis bronchial asthma correct?" Family Practice, vol. 16, no. 2, pp. 112-116, 1999.

[15] O. Lowhagen, "Asthma-a disease difficult to define," Läkartidningen, vol. 102, pp. 3875-3878, 2005.

[16] M. Thomas, R. K. McKinley, E. Freeman, and C. Foy, "Prevalence of dysfunctional breathing in patients treated for asthma in primary care: Cross sectional survey," British Medical Journal, vol. 322, no. 7294, pp. 1098-1100, 2001.

[17] M. Thomas, R. K. McKinley, E. Freeman, C. Foy, and D. Price, "The prevalence of dysfunctional breathing in adults in the community with and without asthma," Primary Care Respiratory Journal, vol. 14, no. 2, pp. 78-82, 2005.

[18] E. Bonde, E. Andersson, J. Brisman, M. Eklöf, K. C. Ringsberg, and K. Torén, "Dissociation of dysfunctional breathing and odour intolerance among adults in a general-population study," The Clinical Respiratory Journal, vol. 7, no. 2, pp. 176-182, 2013.

[19] A. H. Bahrainwala and M. R. Simon, "Wheezing and vocal cord dysfunction mimicking asthma," Current Opinion in Pulmonary Medicine, vol. 7, no. 1, pp. 8-13, 2001.

[20] A. H. Hammo and M. M. Weinberger, "Exercise-induced hyperventilation: a pseudoasthma syndrome," Annals of Allergy, Asthma and Immunology, vol. 82, no. 6, pp. 574-578, 1999.

[21] I. R. Bell, C. S. Miller, and G. E. Schwartz, "An olfactory-limbic model of multiple chemical sensitivity syndrome: possible relationships to kindling and affective spectrum disorders," Biological Psychiatry, vol. 32, no. 3, pp. 218-242, 1992.

[22] E. Millqvist, M. Bende, and O. Löwhagen, "Sensory hyperr eactivity-a possible mechanism underlying cough and asthma-like symptoms," Allergy, vol. 53, no. 12, pp. 1208-1212, 1998.

[23] Å. Johansson, E. Millqvist, S. Nordin, and M. Bende, "Relationship between self-reported odor intolerance and sensitivity to inhaled capsaicin: proposed definition of airway sensory hyperreactivity and estimation of its prevalence," Chest, vol.129, no. 6, pp. 1623-1628, 2006.

[24] "Global Initiative for Chronic Obstructive Lung Disease. Global Strategy for the Diagnosis, Management and Prevention of Chronic Obstructive Pulmonary Disease," NHLBI/WHO Workshop Report 2701: 1-100, Bethesda, National Heart, Lung and Blood Institute, 2001.

[25] L. Löwhagen, "Some procedures used to assess clinical airway hyperreactivity," European Journal of Respiratory Diseases, vol. 131, pp. 215-239, 1983.

[26] K. C. Ringsberg, P. Bjärneman, O. Löwhagen, A. Odén, and $\mathrm{K}$. Torén, "Differences in trigger factors and symptoms between patients with asthma-like symptoms and patients with asthma: development of a basis for a questionnaire," Respiratory Medicine, vol. 96, no. 5, pp. 305-311, 2002.

[27] A. H. Morice, "Chronic cough," Breathe, vol. 3, pp. 165-174, 2006.

[28] K. Torén, T. Gislason, E. Omenaas et al., "A prospective study of asthma incidence and its predictors: the RHINE study," European Respiratory Journal, vol. 24, no. 6, pp. 942-946, 2004.

[29] O. Löwhagen, M. Arvidsson, and K. Pettersson, "Asthma and asthma-like disorder, a 5-year follow-up study," Respiratory Medicine, vol. 96, no. 12, pp. 1040-1044, 2002.

[30] E. Ternesten-Hasséus, O. Lowhagen, and E. Millqvist, "Quality of life and capsaicin sensitivity in patients with airway symptoms induced by chemicals and scents: a longitudinal study," 
Environmental Health Perspectives, vol. 115, no. 3, pp. 425-429, 2007.

[31] W. N. Gardner, "The pathophysiology of hyperventilation disorders," Chest, vol. 109, no. 2, pp. 516-534, 1996.

[32] H. Hornsveld and B. Garssen, "Hyperventilation syndrome: an elegant but scientifically untenable concept," Netherlands Journal of Medicine, vol. 50, no. 1, pp. 13-20, 1997.

[33] O. Löwhagen, M. Arvidsson, P. Bjärneman, and N. Jörgensen, "Exercised-induced respiratory symptoms are not always asthma.," Respiratory Medicine, vol. 93, no. 10, pp. 734-738, 1999.

[34] S. Jack, H. B. Rossiter, M. G. Pearson, S. A. Ward, C. J. Warburton, and B. J. Whipp, "Ventilatory responses to inhaled carbon dioxide, hypoxia, and in idiopathic hyperventilation," The American Journal of Respiratory and Critical Care Medicine, vol. 170, no. 2, pp. 118-125, 2004.

[35] E. Ternesten-Hasséus, E. L. Johansson, M. Bende, and E. Millqvist, "Dyspnea from exercise in cold air is not always asthma," Journal of Asthma, vol. 45, no. 8, pp. 705-709, 2008.

[36] J.van Dixhoorn and H. J. Duivenvoorden, "Efficacy of Nijmegen questionnaire in recognition of the hyperventilation syndrome," Journal of Psychosomatic Research, vol. 29, no. 2, pp. 199-206, 1985.

[37] "Socialstyrelsens riktlinjer för förebyggande, diagnostik, behandling och rehabilitering av astma och KOL," Artikelnummer 2203-102-4, 2003.

[38] K. C. Ringsberg, M. Lepp, and B. Finnström, "Experiences by patients with asthma-like symptoms of a problem-based learning health education programme," Family Practice, vol. 19, no. 3, pp. 290-293, 2002.

[39] K. C. Ringsberg and T. Timpka, "Clinical health education for patients with asthma-like symptoms but negative asthma tests," Allergy, vol. 56, no. 11, pp. 1049-1054, 2001. 


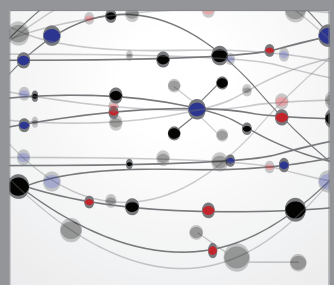

The Scientific World Journal
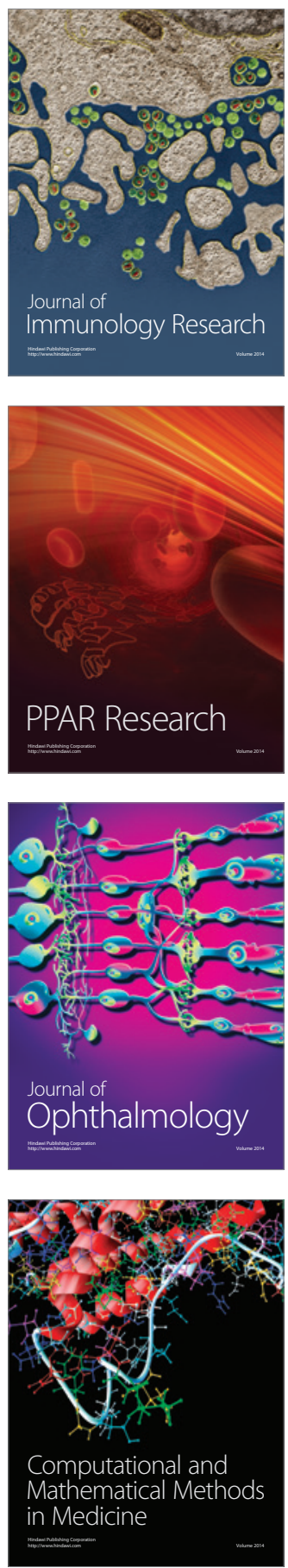

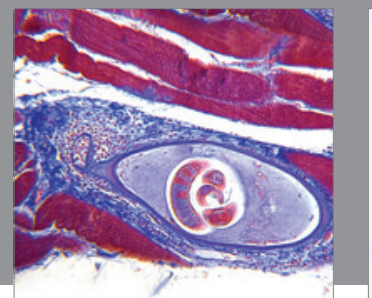

Gastroenterology

Research and Practice
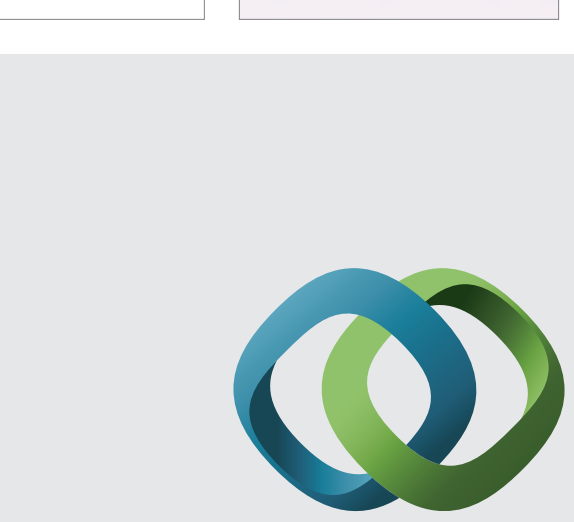

\section{Hindawi}

Submit your manuscripts at

http://www.hindawi.com
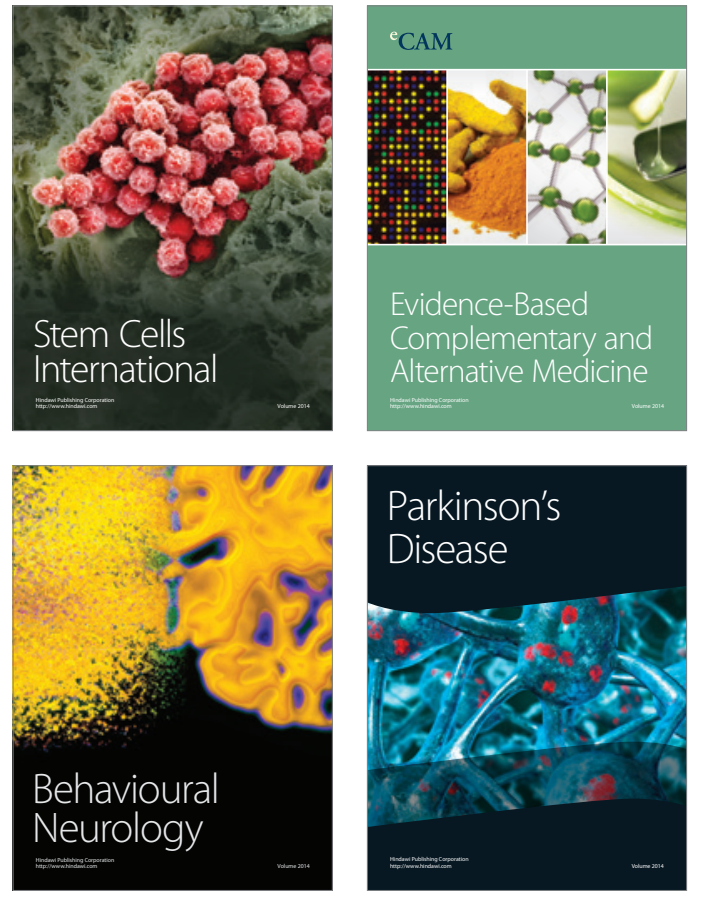
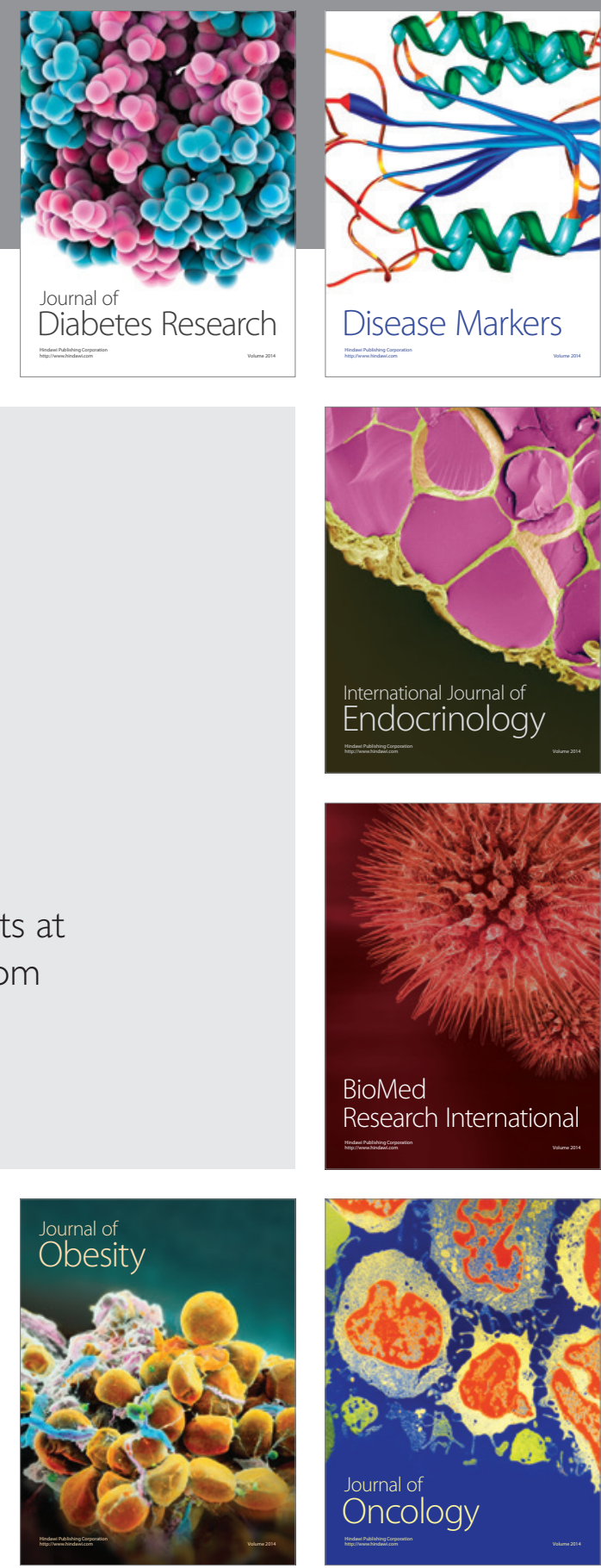

Disease Markers
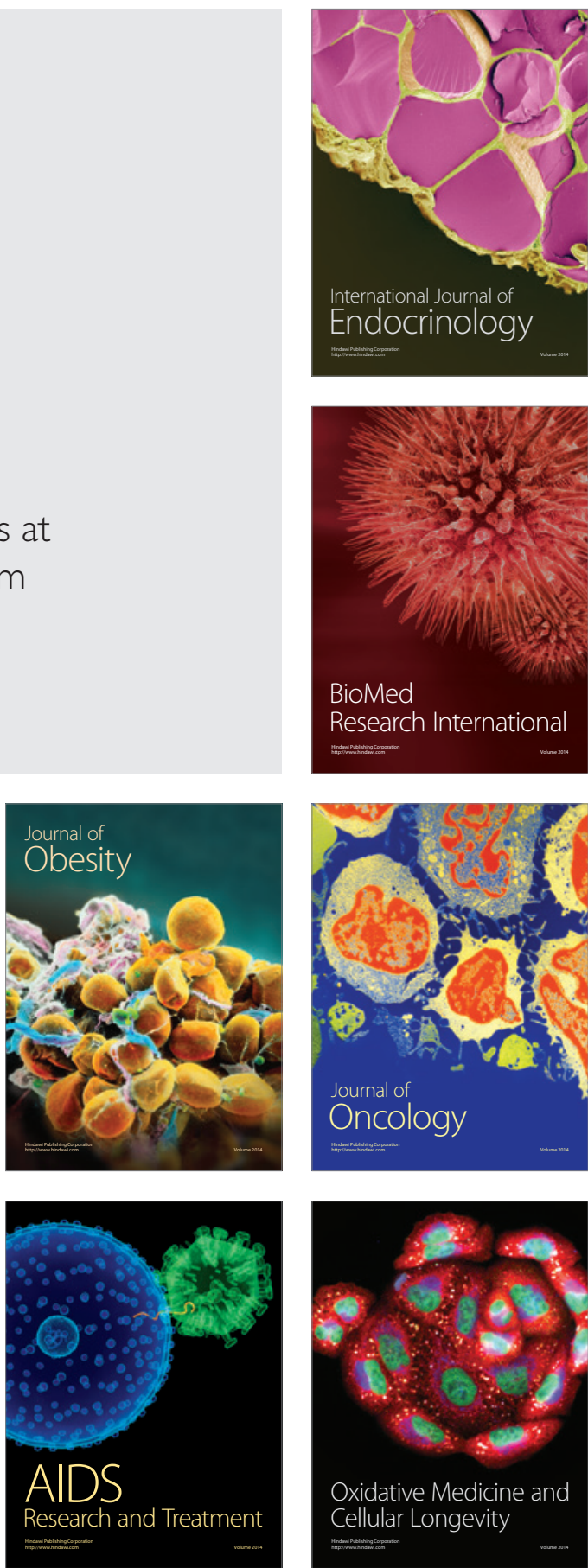